\title{
A robust 3D finite element model for concrete columns confined by FRCM system
}

\author{
Majid M.A. Kadhim ${ }^{1 *}$, Mohammed J Altaee ${ }^{1}$, Ali Hadi Adheem², and Akram R. Jawdhari ${ }^{3}$ \\ ${ }^{1}$ Faculty (lecturer), College of Engineering, University of Babylon, Hilla, Iraq. \\ ${ }^{2}$ Faculty (lecturer), Kerbala Technical Institute, Al-Furat Al-Awsat Technical University, 56001 \\ Kerbala, Iraq. \\ ${ }^{3}$ Faculty (lecturer), Department of Construction and Projects, University of Babylon, Hilla, Iraq.
}

\begin{abstract}
Fibre reinforced cementitious matric (FRCM) is a recent application of fibre reinforced polymer (FRP) reinforcement, developed to overcome several limitations associated with the use of organic adhesive [e.g. epoxies] in FRPs. It consists of two dimensional FRP mesh saturated with a cement mortar, which is inorganic in nature and compatible with concrete and masonry substrates. In this study, a robust three-dimensional (3D) finite element (FE) model has been developed to study the behaviour of slender reinforced concrete columns confined by FRCM jackets, and loaded concentrically and eccentrically. The model accounts for material nonlinearities in column core and cement mortar, composite failure of FRP mesh, and global buckling. The model response was validated against several laboratory tests from literature, comparing the ultimate load, loadlateral deflection and failure mode. Maximum divergence between numerical and experimental results was $12 \%$. Following the validation, the model will be used later in a comprehensive parametric analysis to gain a profound knowledge of the strengthening system, and examine the effects of several factors expected to influence the behaviour of confined member.
\end{abstract}

\section{Introduction}

Deterioration of reinforced concrete structures is a major problem worldwide and is attributed to many factors, including increased loads beyond the design ones, exposure to environmental conditions such as freeze-thaw cycles, moisture, de-icing agents, design and/or construction errors, etc. [1]. Many techniques have been proposed to strengthen/repair severed structures and extend their service lives. Some of these techniques employ traditional materials such as concrete overlay or steel jacket [1]. However, due to several problems, including corrosion of steel, increased member dimensions when using concrete overlay, the civil engineering community is continuously seeking more efficient and economic solutions. Fibre reinforced polymer (FRP) composites were initially introduced in the aerospace and automotive industries, and adopted later in the construction

\footnotetext{
* Corresponding author: eng.majid.mohammed@uobabylon.edu.iq
} 
industry, due to several advantages such as high strength, light weight, resistance to corrosion, and ease of application [2].

Fibre reinforced cementitious matrix (FRCM) is a recent retrofit system developed to overcome the limitations associated with organic matrices. It consists of FRP composite usually in the form of two dimensional mesh, impregnated with cement (inorganic) mortar [3]. The FRP mesh can be Carbon, Glass, Basalt, or Polyparaphenylene Benzobisoxazole (PBO) fibers [3]. Laboratory tests have been performed to validate the effectiveness of FRCM system in strengthening concrete members, mainly for shear and flexural applications [4-6], and few for torsion retrofits [3]. It was found that the use of this technique has a great potential as a strengthening technique for the concrete structures.

The strengthening of compression members using FRCM technique has also been explored, although in a limited number of studies [7-12]. These studies can be divided into two main categories: strengthening of short (plain) concrete columns [7-9] and strengthening of slender reinforced concrete columns [10-12]. In the first category, the impact of many parameters such as cross-section shape, $e / h$ ratio, fibre reinforcement ratio and fibres orientation, were investigated. It was found that the FRCM jacketing had a significant contribution in improving strength and deformability of the tested samples [7-9].

However, few studies can be found investigating the employment of FRCM technique in strengthening slender reinforced concrete columns. In these studies, parameters investigated were the strengthening ratio, fibres orientation and the eccentricity-to-section ratio [10-12]. To the authors' best knowledge, there have been no attempts to examine the effects of slenderness ratio and response of columns under eccentric loading that is applied outside the cross-section's core. Thus, the main aim of this paper is to develop and validate a robust three-dimensional (3D) finite element (FE) model, capable of predicting the behaviour of RC columns strengthened using FRCM technique. Following the validation, the model can be used in a comprehensive parametric analysis to examine the effects of a wide range of parameters influencing the effectiveness of this technique.

\section{Experimental investigation}

The study carried out by Trapko [10] was used as benchmark to validate the finite element model. Six columns were analysed, which had a square cross-section of $200 \times 200$ $\mathrm{mm}$ and a height of $1500 \mathrm{~mm}$ [Fig. 1 (a, b)]. Three of these columns were strengthened with FRCM technique and three were un-strengthened, serving as reference specimens. The $\mathrm{RC}$ columns were tested under pure axial compression load or under eccentric load with two different eccentricity values: $h / 6$ and $h / 12$.(Table 1). The nominal compressive $\left(f_{c}^{\prime}\right)$ strength of the concrete was $48.7 \mathrm{MPa}$. The vertical reinforcing steel consisted of four $12 \mathrm{~mm}$ bars; while $6 \mathrm{~mm}$ closed-stirrups was provide as shear reinforcement, with a spacing of $55 \mathrm{~mm}$ at ends and $170 \mathrm{~mm}$ in the central section, Fig.1 (a). The yield stress $\left(f_{y}\right)$ of longitudinal and transverse reinforcements were $500 \mathrm{MPa}$ and $220 \mathrm{MPa}$, respectively.

Table 1: Details and key results of the analysed columns

\begin{tabular}{|c|c|c|c|c|c|c|c|c|}
\hline \multirow[t]{2}{*}{$\begin{array}{l}\text { Specimen } \\
\text { No. }\end{array}$} & \multicolumn{2}{|c|}{ FRCM layout } & \multirow[t]{2}{*}{$\begin{array}{c}\text { Eccentricity } \\
(e),(\mathrm{mm})\end{array}$} & \multicolumn{2}{|c|}{$\begin{array}{c}\text { Maximum } \\
\text { load, } P_{\max }(\mathrm{kN})\end{array}$} & \multirow[t]{2}{*}{$\begin{array}{c}\% \\
\text { Diff. }^{3}\end{array}$} & \multirow[t]{2}{*}{$\begin{array}{c}P_{y-F E M^{4}} \\
(\mathbf{k N})\end{array}$} & \multirow[t]{2}{*}{$\begin{array}{c}\% \\
\text { increase }\end{array}$} \\
\hline & $x$-dir 1 & $y$-dir ${ }^{2}$ & & Exp. & FEM & & & \\
\hline C-0 & - & - & 0 & 2213.8 & 2247.4 & 1.52 & 2122.8 & -5.54 \\
\hline C-16 & - & - & 16 & 1652.0 & 1648.3 & -0.22 & 1611.3 & -2.24 \\
\hline C-32 & - & - & 32 & 1516.4 & 1331.0 & -12.33 & 1277.7 & -4.00 \\
\hline $\mathrm{C}-1 \mathrm{H}-0$ & 1 layer & - & 0 & 2586.8 & 2469.8 & -4.52 & 2188.1 & -11.40 \\
\hline C-1H-16 & 1 layer & - & 16 & 1956.8 & 1810.3 & -7.49 & 1653.8 & -8.64 \\
\hline C-1H-32 & 1 layer & - & 32 & 1596.0 & 1460.4 & -8.49 & 1300.7 & -10.93 \\
\hline
\end{tabular}


${ }^{1}$ Horizontally oriented FRCM layer.

2 Vertically oriented FRCM layer.

$3=\frac{P_{\max -F E M}-P_{\max }-\text { Exp. }}{P_{\max }-E x p} \times 100$

${ }^{4}$ Load at first yielding of longitudinal steel reinforcement.

$5=\frac{P_{y-F E M}-P_{\max -F E M}}{P_{\max }-F E M} \times 100$

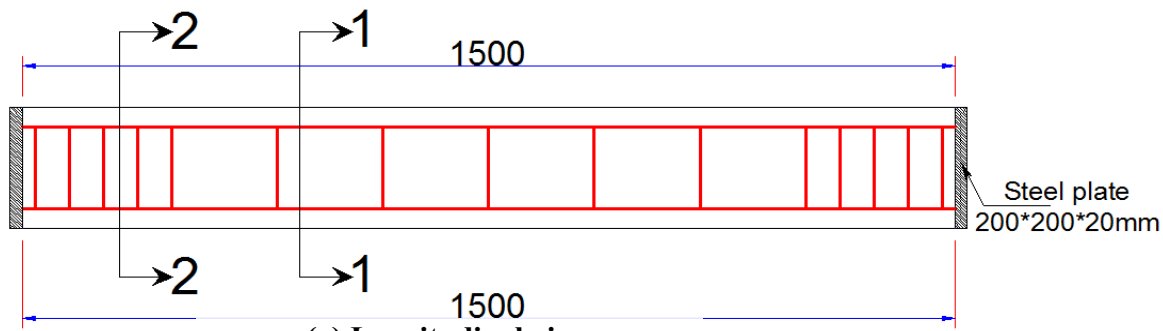

(a) Longitudinal view

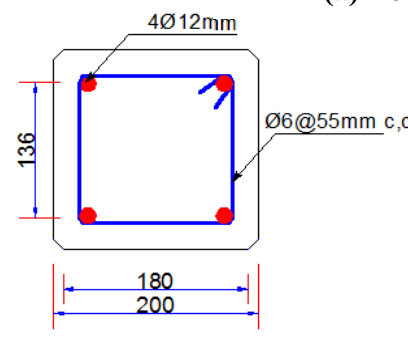

Sec. 2-2

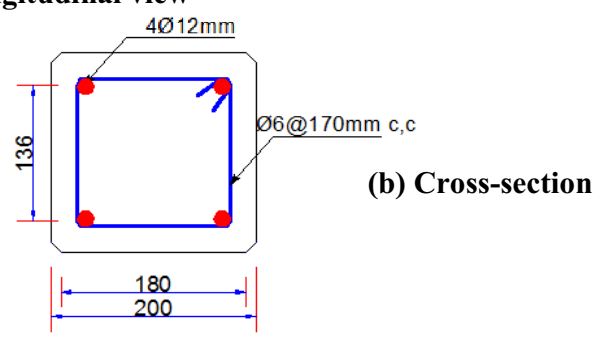

Sec. 1-1

Fig.1. details of tested specimens.

\section{Finite element modelling}

The numerical models for the columns tested by Trapko [10] were constructed using the commercial finite element software ANSYS APDL 17.2 [13]. Appropriate element types were used for the different parts of the strengthened column, and interfaces between dissimilar materials. Both material and geometric nonlinearities were considered, providing an accurate simulation of possible failure modes such as crushing and cracking in concrete and cementitious mortar, column buckling, and rupture of strengthening fibres. The concrete core was modelled with the eight-node SOLID185 brick element which has three translational degrees of freedom per node. This element was also used to model the steel plates at column ends used in the experimental programme (see Fig.2). The four-node shell element (SHELL181) was employed to model FRCM jacket. This element type has six degrees of freedom, three of which are translational and the remaining three are rotational. The FRCM strengthening jacket is assumed as a multilayer shell in which there is no slippage between these layers is assumed. However, CONTA173 and TARGE169 element are used to model the bond region between the column and FRCM system.

The concrete material and cement mortar were modelled in compression with the Drucker-Prager (DP) concrete model, available in newer versions of ANSYS. DP-concrete is an improved version of the traditional DP model, adding several enhancements such as separate failure criteria for tension and compression, nonlinear stress-strain response in compression, stress softening/hardening in tension and compression, and post-cracking stress stiffening in tension. Confinement due to steel stirrups (in control specimens) and due 
to FRCM jackets (in strengthened samples) were considered, using the theoretical models of Kent and Park [14] and Lam and Teng [15], respectively.

Concrete columns confined by FRP jackets/sheets have been modelled successfully with the Drucker-Prager (DP) plasticity model $[16,17]$. Conventional DP model assumes an elastic-perfectly plastic response under both tensile and compressive stresses, and utilizes a modified version of the Von Mises yield criterion to account for the effects of hydrostatic pressure [16]. However, this model is unable to simulate the large difference in tensile and compressive responses of concrete and doesn't include softening after cracking or crushing [13]. ANSYS 17.2 software includes an extended version of DP (extended DP) which combines two DP yield surfaces, one for tension and one for compression, to represent the material behaviour more realistically [13]. Several hardening/softening behaviours for tension and compression, including linear, exponential, piece-wise linear, and fracture energy, are available with the model. In this study, the extended DP model is used to model the concrete columns strengthened with FRCM jackets, using the linear softening behaviour.
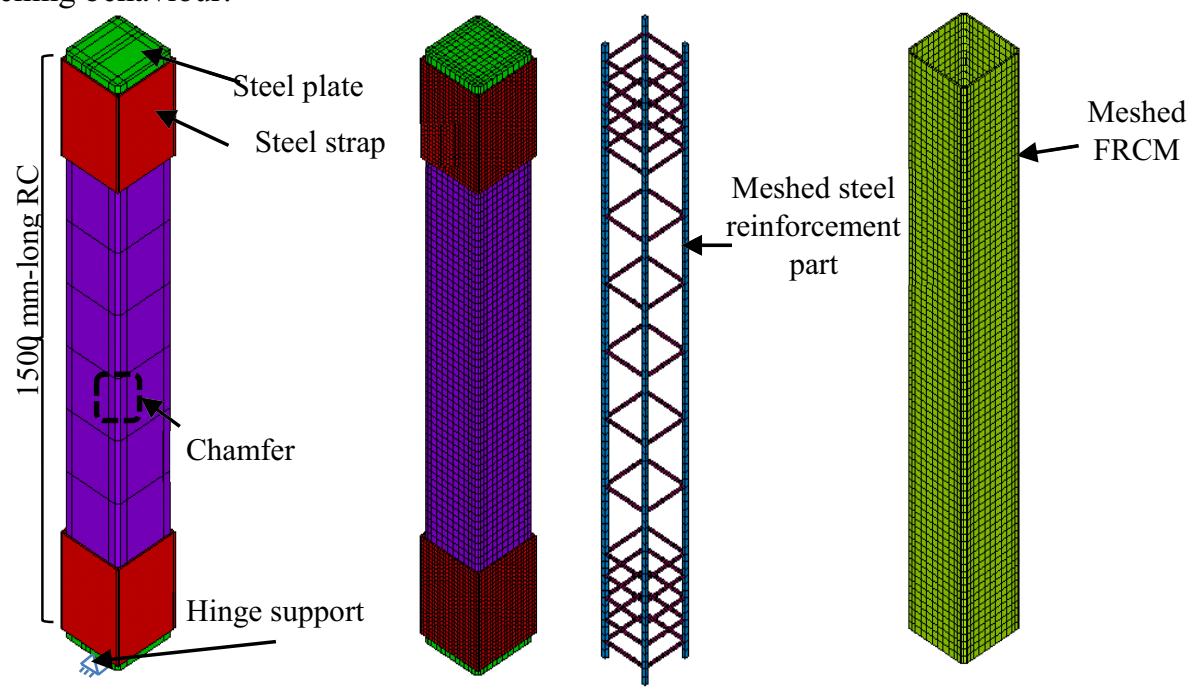

Fig.2. Details of FE model for columns.

The fibres in FRCM system were modelled as linear elastic material up to failure, which was defined explicitly using ANSYS composite damage option and maximum stress criteria for damage initiation. Damage evolution in the fibres was simulated by introducing a stiffness degradation factor of 0.95 for affected modes of failure. Steel reinforcement was modelled as elastic-perfectly plastic material.

\section{Verification results}

The finite element results of pin-ended RC columns developed in this research were validated against experimental results reported by Trapko [10]. The ultimate load values obtained from tests are compared with the corresponding values, obtained from the finite element analysis as listed in Table 1. It can be noticed from this table that a good agreement exists between the experimental and finite element results with the maximum divergence about $12 \%$. An interesting observation in the FE results listed in Table $\mathbf{1}$ is that the analysed columns failed with the yielding of the longitudinal reinforcement. This observation was made by calculating the difference between the ultimate and yield loads from FEM models which was found to be in maximum 5\% and $11 \%$ for un-strengthened and strengthened 
columns respectively. This means that the columns were unable to carry extra load after the yield point. This failure mode was significantly different from that reported in the experimental observations since it was difficult to measure the stress along the steel reinforcement bars.

The comparison between the experimental and finite element load-lateral deflection demonstrates that the finite element predictions were in good agreement when compared to corresponding experimental data as shown in Fig.3. In most cases, the finite element loadlateral deflection continues until the applied load was decreased.
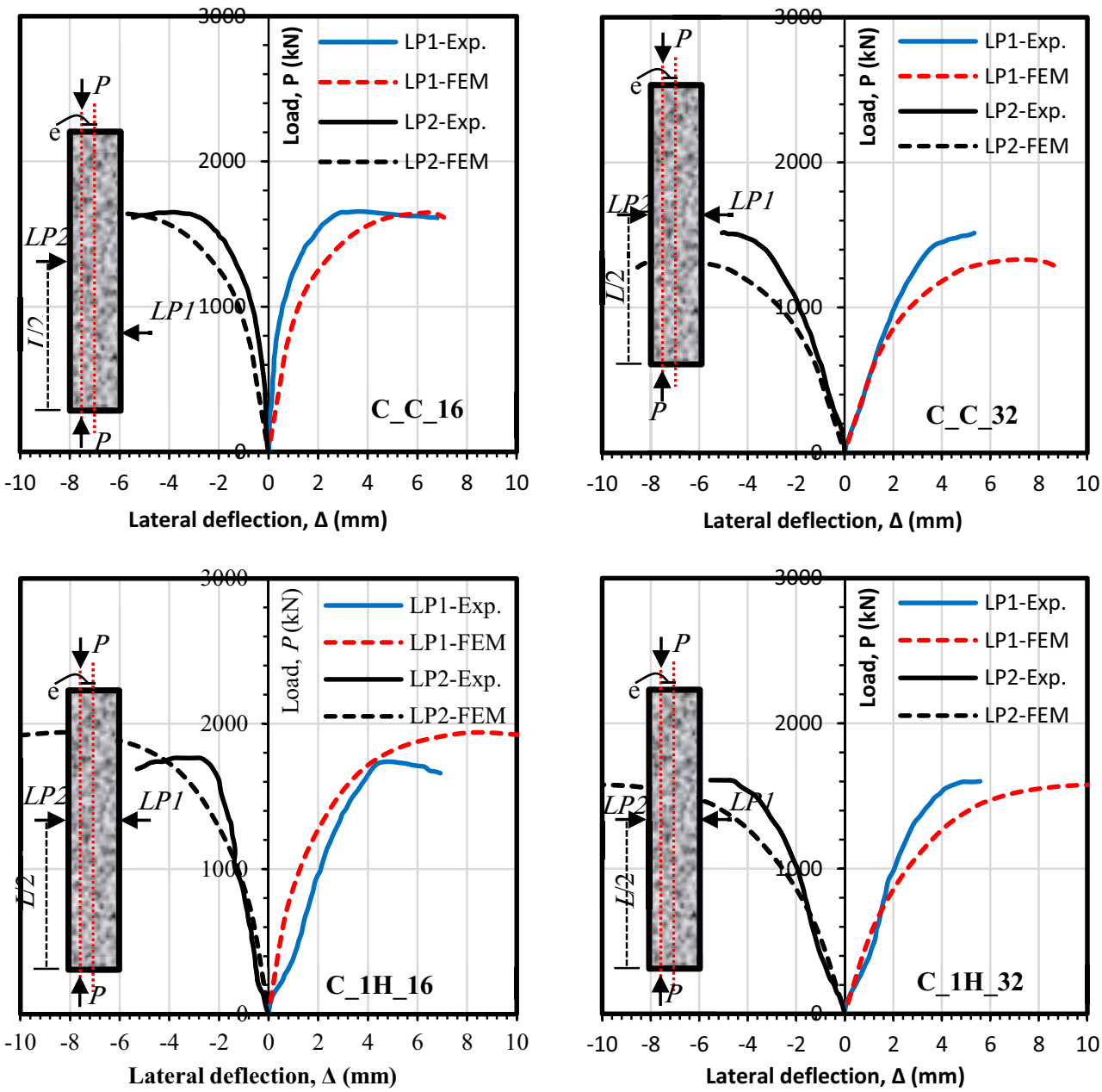

Fig.3: Comparison of load - lateral deflection obtained from experimental and FE modelling

Generally, it can be concluded that the FE model is able to predict the experimental response of RC columns strengthened with FRCM technique with high level of accuracy and this model can be used later to perform a comprehensive parameter analysis on this strengthening technique, examining a wide range of parameters that may affect the contribution of this technique in improving $\mathrm{RC}$ columns response. It should be noted that the FE model is verified in the current study against experimental results for RC columns tested under quasi-static loading rate. Thus, further research based on this verification will include this kind of load only. 


\section{Conclusions}

A nonlinear finite element model of eccentrically loaded reinforced concrete columns strengthened with FRCM technique has been developed and validated in this research. The model was verified against experimental results obtained from literature. The verification of the FE model was achieved by making a comparison between the ultimate load, failure mode and load-lateral deflection gained from FE modelling and the test data. The comparison between the FE and experimental results demonstrated that the FE model can accurately predict the response of the eccentrically loaded RC columns strengthened with FRCM system. Thus, this model can be used in further studies to investigate more parameters such as the slenderness ratio, cross-section shape, width-to-height ratio of rectangular column, eccentric load outside column's cross-section, FRCM layout...etc.

\section{References}

1.A. Jawdhari, 2016 "Behavior of RC beams strengthened in flexure with spliced CFRP rod panels." Doctoral dissertation, Paper 37. http://uknowledge.uky.edu/ce etds/37.

2.A. Jawdhari, A. Peiris and I. Harik, 2018 "Experimental study on RC beams strengthened with CFRP rod panels." Eng. Struct. 173: p. 693-705.

3.M.Y. Alabdulhady, L.H. Sneed, O.I. Abdelkarim and M.A. ElGawady, 2017 "Finite element study on the behavior of RC beams strengthened with PBO-FRCM composite under torsion." Compos. Struct. 179: p. 326-339.

4.L. Ombres, 2011 "Flexural analysis of reinforced concrete beams strengthened with a cement based high strength composite material." Compos. Struct. 94: p. 143-155.

5.A. D'AmbrisiF. Focacci, 2011 "Flexural strengthening of RC beams with cement-based composites." J Compos Constr. 15: p. 707-720.

6.M.M. Kadhim, A.H. Adheem and M.J. Altaee, 2019 "Shear Strengthening of RC Beams with FRCM Technique." Int. J. Eng. Technol. 8: p. 169-176.

7.T.C. Triantafillou, C.G. Papanicolaou, P. Zissimopoulos and T. Laourdekis, 2006 "Concrete confinement with textile-reinforced mortar jackets." ACI Mater. J. 103: p. 28.

8.A. Peled, 2007 "Confinement of damaged and nondamaged structural concrete with FRP and TRC sleeves." J. Compos. Constr. 11: p. 514-522.

9.L. Ombres, 2014 "Concrete confinement with a cement based high strength composite material." Compos. Struct. 109: p. 294-304.

10.T. Trapko, 2014 "Effect of eccentric compression loading on the strains of FRCM confined concrete columns." Constr Build Mater. 61: p. 97-105.

11.T. Trapko, 2014 "Behaviour of fibre reinforced cementitious matrix strengthened concrete columns under eccentric compression loading." Materials \& Design (19802015). 54: p. 947-954.

12.L. OmbresS. Verre, 2015 "Structural behaviour of fabric reinforced cementitious matrix (FRCM) strengthened concrete columns under eccentric loading." Composites Part B. 75: p. 235-249.

13.ANSYS, 2016 "Release 17.2 Documentation for ANSYS." Version 17.2, ANSYS Inc., Canonsburg, PA, USA.

14.D.C. KentR. Park, 1971 "Flexural members with confined concrete." Journal of the Structural Division.

15.L. LamJ. Teng, 2003 "Design-oriented stress-strain model for FRP-confined concrete." Constr. Build. Mater. 17: p. 471-489.

16.S.Y. Ghanem, 2016 "Circular RC columns partially confined with FRP."

17.A. Mirmiran, K. Zagers and W. Yuan, 2000 "Nonlinear finite element modeling of concrete confined by fiber composites." Finite Elem. Anal. Des. 35: p. 79-96. 